\title{
NUTRITIONAL STATUS AND CLINICAL OUTCOME IN POST-TERM NEONATES UNDERGOING SURGERY FOR CONGENITAL HEART DISEASE
}

1

2

3

4

5

Dr Rebecca Mitting ${ }^{1}$ MRCPCH, Dr Luise Marino ${ }^{2}$ PhD, Dr Duncan Macrae ${ }^{1}$ FRCPCH FRCA, Dr Nitin Shastri ${ }^{1}$ MRCPCH, Dr Rosan Meyer ${ }^{3}$ PhD, Dr Nazima Pathan ${ }^{4}$ PhD FRCPCH

${ }^{1}$ Royal Brompton and Harefield NHS Foundation Trust, London, UK

${ }^{2}$ Southampton University Hospital NHS Foundation Trust, Southampton,UK

${ }^{3}$ Great Ormond Street Hospital, London, UK

${ }^{4}$ University of Cambridge, Cambridge, UK

Name of institution where work was performed:

Royal Brompton Hospital, Sydney Street, London, SW3 6NP UK

Correspondence to (reprints will not be ordered):

Dr Nazima Pathan, University Department of Paediatrics, University of Cambridge

Addenbrookes Hospital, Cambridge , CB2 OQQ

Email: np409@medschl.cam.ac.uk

Telephone: 01223336883

Financial Support: The authors are grateful to the Cardiovascular Biomedical Research Unit at the Royal Brompton Hospital for Institutional support.

Keywords: Neonatal, Congenital Heart disease, Nutrition, Outcomes, Surgery 


\section{ABSTRACT}

\section{Objective}

Poor growth is a common complication in infants with congenital heart disease. There has been much focus on low birth weight as having increased risk of adverse outcomes following neonatal heart surgery. In this study we examined whether pre-operative nutritional status, measured by admission weight for age $Z$ (WAZ) score was associated with post-operative clinical outcome.

\section{Design}

Retrospective case series

\section{Patients}

Neonates undergoing surgery for congenital heart disease. Those undergoing ductus arteriosus ligation alone were excluded. Children with co-existing non cardiac morbidity were excluded. Outcome variables included incidence of post-operative complications (including sepsis, delayed chest closure, renal impairment and necrotizing enterocolitis), duration of ventilation, intensive care stay and post-operative mortality and mortality at 1 year after surgery.

\section{Setting}

Paediatric Cardiac Intensive Care Unit at the Royal Brompton Hospital

\section{Measurements and Main Results}

248 neonates fulfilled the entry criteria. Median (IQR) age was 7 (2-15) days, median (IQR) weight 3.3 (2.91-3.6) $\mathrm{kg}$ and median WAZ score -0.77 (-1.44-0.01). 28 (11\%) children had a WAZ score of less than 2. There was no evidence that children with lower WAZ score had less severe surgery as measured by the Risk Adjustment for Congenital Heart Surgery 1 (RACHS-1) score. In multivariable regression analysis, the WAZ on admission had strong correlation with the number of days free of respiratory support (invasive and non-invasive ventilation) at 28 days $(p<0.0001)$ and with all-cause mortality at 1 year $(p=0.001)$.

\section{Conclusions}

Poor nutritional status as measured by WAZ is associated with adverse short and long term outcomes in neonates undergoing surgery for congenital heart disease. 


\section{INTRODUCTION}

Congenital heart disease (CHD) is a significant health burden, affecting between 0.3 and $1.5 \%$ of all pregnancies [1]. Children with congenital heart disease are known to exhibit early and progressive falls in their growth trajectory compared to healthy children, with reductions in weight for age (WAZ) score, head circumference and length for age $Z$ score $[2,3]$. It is also known that surgery and bypass, and the burden of cardiac failure and chronic disease results in significant metabolic and nutritional stress. Furthermore inadequate nutritional intake in the post-operative period results in further challenges to restoring normal growth parameters $[4,5]$.

Early nutritional support is known to be important, particularly in those undergoing surgery in early life, where there is little reserve during a critical time for brain development. As there is an increasing trend towards primary repair of cardiac defects in the early neonatal period [6-10], it is important to identify infants who are at increased risk of poor outcome as a result of their pre-surgical nutritional status. Babies who are growth restricted (birthweight less than $2.5 \mathrm{~kg}$ ) have been shown to have poorer outcomes [11-13]. Whilst intra-uterine growth restriction is an important contributor to low weight at the time of surgery in the first week, inadequate post-natal nutrition may be a significant factor for those babies with more complex cardiac lesions or those operated on later in the neonatal period, and operative weight as well as maturity may affect short and longer term outcomes [13-16]. Finally, it has been shown that necessary calorie and protein intake is often not achieved for up to two weeks after surgery, further impacting on poor nutrition status [17] increasing the risk of later morbidity [18] and prolonged growth restriction.

We wanted to determine whether nutritional status, as measured by WAZ score, had any impact on short and longer term outcomes in neonates undergoing palliative or corrective surgery for congenital heart disease in the first month of life. We hypothesised that children who had lower WAZ score would have poorer clinical outcomes. 


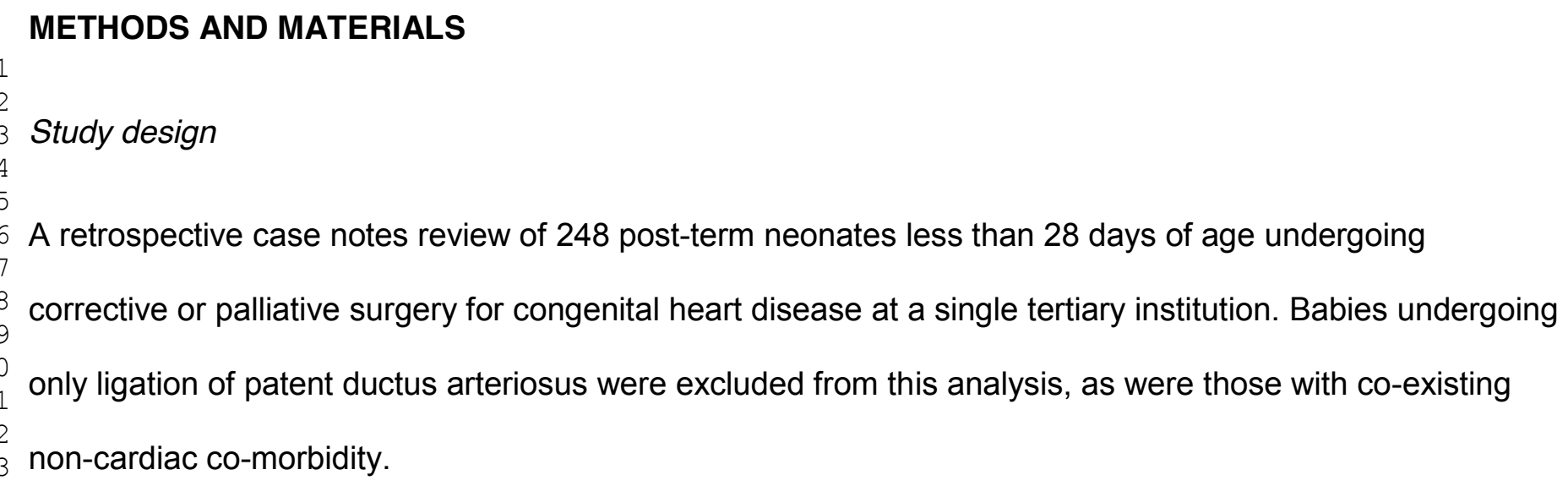

Both R -statistical software version 3.0.1 2012 and SPSS version 20 (Chicago, USA) were used to analyse the data. The primary outcome variable was mortality at 1 year. Secondary outcomes included postoperative mortality, days free of invasive and/or non-invasive respiratory support at 28 days, days free of intensive care at 28 days and post-operative complications. The primary predictor variable was WAZ at the 
time of surgery. Potential covariates included absolute weight, post-operative lactate level, the type of cardiac lesion and surgical approach (Univentricular or biventricular repair, RACHS-1 score).

2 An initial Spearman rank correlation analysis was undertaken to explore the association of WAZ Score with a range of linear clinical variables. Mann Whitney $U$ Test was used to test the association between $Z$ score and categorical variables. Multivariable logistic regression analysis was performed to adjust for confounders and establish which factors, including WAZ score, impacted on the mortality at 1 year. We 10 a continuous variable. Statistical significance was set at $p$ 0.05. Unless specified otherwise values are shown as median and IQR. 


\section{RESULTS}

\section{Study population:}

We reviewed case notes of all neonates undergoing congenital heart surgery (excluding surgical duct ligation) from 2005-2010. 264 neonates underwent surgery in this period. Of these 16 had pre-existing, non cardiac comorbidity and were excluded from the analysis. These included Situs inversus, Trachealoesophageal defects, Chromosomal anomalies, Choanal stenosis, Renal dysplasia, Scimitar syndrome and Neonatal Thrombophilia. Of the remaining 248 babies, $156(62.9 \%)$ were male, and $92(37.1 \%)$ were female. $16(6.5 \%)$ died post-operatively. 1 year post surgical mortality was $11.7 \%$ (29/248). Further demographic data are shown in Table 1. Three babies underwent 2 surgeries during their first month of life. Each surgical intervention was treated as a separate episode since the patients had been discharged from PICU and readmitted. All three babies survived PICU and were alive at one year after surgery.

\section{Nutritional status:}

$60.9 \%(151 / 248)$ neonates had a normal WAZ ( $\geq-1) .28 .2 \%(70 / 248)$ had a mild degree of malnutrition (WAZ $<-1$ to $\leq-2)$, and $10.9 \%(27 / 248)$ had more severe malnutrition $(<-2)$.

\section{Surgical risk factors:}

Using the RACHS-1 score as a marker of surgical complexity and classifying whether the cardiac lesion was univentricular or biventricular, we examined whether underweight infants had a different surgical approach. The distribution of WAZ score was the same across the RACHS-1 score groups $(p=0.47)$ and there was no significant difference in WAZ score amongst those having univentricular or biventricular repair $(p=0.106)$.

Children with lower WAZ (less than -2) were more likely to need increased non-invasive respiratory support post-operatively (table 2), although the duration of invasive ventilation and PICU stay were not different between nutrition groups.

Median WAZ scores did not differ significantly for those who had post-operative complications compared to those who had an uncomplicated recovery (overall $p=0.26$ ), including sepsis, delayed chest closure, neurological complications and necrotizing enterocolitis.

Regression analysis of the association between admission WAZ score and clinical outcome: 
Analysis of risk factors for the length of post-operative intensive care, respiratory support and with mortality (post-operative and at 1 year after surgery) in the entire cohort showed that admission WAZ score had a 1 significant association with days free of respiratory support at 28 days (invasive and/or non-invasive) as shown in Table 3a. We analysed survival in the early post-operative period (hospital mortality) as well as 1 year after operation date. WAZ did not have an association with hospital mortality $(p=0.31)$. However we found a significant impact of a low WAZ score, on mortality at 1 year of age $(p=0.002)$. Odds of death were increased by a factor of 2.36 and 1.1 for every unit decrease in WAZ and age respectively (Table 3b).

\section{DISCUSSION:}

In this study we found that low admission WAZ was associated with prolonged respiratory failure and increased late mortality in neonates undergoing surgery for congenital heart disease. We found that admission WAZ score had a significant association with days free of respiratory support at 28 days (invasive and/or non-invasive). We noted in particular an increased use of non-invasive ventilation. Whilst WAZ did not appear to be associated with early post-operative death, there was significantly increased risk of late death (survival status at 1 year after surgery).

Several factors have been implicated in leading to protein-energy malnutrition in children with CHD, including the challenge of delivery, excessive losses and altered resting energy expenditure. Whilst it is recognized that improving nutrition status prior to surgery may be of benefit, the provision of sufficient energy and protein during the post-operative period is particularly challenging as fluid restrictions and the amount of volume required for supportive drug therapy limits the amount of volume available for feed, further exacerbating malnutrition [21]. A number of studies have reported that infants with single-ventricle physiology experience a $1 \mathrm{Z}$ score decrease between neonatal surgery and discharge from hospital [22]. In order to improve the nutritional status decreasing the risk of late mortality more needs to be done to determine novel ways of delivering sufficient nutrition support [23].

We have previously reported an increase in REE in children following cardiac surgery and in particular that children with malnutrition had an increased expenditure, further impacting on the energy deficit often seen in these children[24]. 
An important consideration on the causes of low WAZ in neonates is the role of Intra-uterine growth retardation, which is likely to have been an important component of the WAZ score in this population - our

median age at time of surgery was 7 days after birth. Future studies should examine the changes in WAZ and other markers of nutritional status (including weight-height $Z$ score and anthropometry) serially following surgery for congenital cardiac lesions, to track the association between nutritional intake, growth and clinical, developmental and functional outcomes.

Children with congenital heart disease often have co-morbidities that may affect the ability to swallow or absorb feeds effectively. In addition prolonged intubation and hospitalization is likely to add to swallowing problems and oral aversion. Gastro-esophageal reflux is relatively common in neonates and young infants with congenital heart disease, and may reduce the success or oral feeds at the volumes needed to restore growth patterns[25]. Previous studies have demonstrated that the presence of comorbidities contributes to feeding difficulties and poorer pre and post-operative growth [26] in children with congenital heart disease, but our data suggests that malnutrition affects clinical outcome from surgery even in those neonates without co-existing comorbidity.

Our study is limited by the fact that apart from 1 year mortality, we do not have data on long term outcomes. Subsequent surgery and late complications are likely to have been important contributors to 1 year mortality, and would be an important component of a future prospective study to examine the influence of low neonatal WAZ on long term outcomes, including neurodevelopmental, feeding and growth as well as hospital reattendances and other organ morbidities. There was no association between WAZ and RACHS1 score suggesting that the severity of the surgical interventions undertaken in the neonatal period were not that different between the malnutrition groups. A prospective study to examine the relationship of neonatal WAZ and the need for further surgeries and long term morbidity is needed to examine this phenomenon.

It would also have been interesting to have more detailed information on the type and route of feeding. A future prospective study could examine whether early enteral nutrition or use of parenteral nutrition might affect clinical outcomes, or whether breast milk has any protective effects. In addition, the impact of prenatal growth restriction is clearly of importance in a neonatal population. It would seem that smaller babies were more likely to have staged corrective repair than a full correction. However, since WAZ did not differ significantly across different RACHS-1 score severities of surgery, it would appear that surgery for severe lesions was undertaken regardless of nutritional status and a longer term study on nutrition and outcomes is needed to examine whether increasing nutrient supply, particularly protein, pre-operatively 
may be of benefit to counteract the adverse effects of low WAZ in neonates undergoing surgery for congenital heart disease. In addition our study does not have data on length and head circumference, 1 which would have provided data on wasting and stunting and the impact on morbidity and mortality. Followup growth measurements would be useful to examine whether neonates exhibit compensatory increases in growth if they had low pre-surgical WAZ.

Since this was an observational study, no power calculation was performed to determine sample size.

However the observed strong relationship between WAZ on admission and some of the markers of clinical outcome warrants further investigation in a prospective study.

Our analysis suggests that malnutrition as measured by the simple assessment of WAZ is a reliable predictor of the need for prolonged respiratory support and the risk of late mortality in neonates undergoing congenital heart surgery. As a marker, it could be used as a guide to highlight patients needing dietetic intervention preceding surgery to improve nutritional state and potentially reduce longer term morbidity. 


\section{REFERENCES:}

1. Hoffman JI, Kaplan S: The incidence of congenital heart disease. Journal of the American College of Cardiology 2002, 39(12):1890-1900.

2. Thommessen M, Heiberg A, Kase BF: Feeding problems in children with congenital heart disease: the impact on energy intake and growth outcome. Eur J Clin Nutr 1992, 46(7):457-464.

3. Naeye RL: Anatomic features of growth failure in congenital heart disease. Pediatrics 1967, 39(3):433-440.

4. Nydegger A, Bines JE: Energy metabolism in infants with congenital heart disease. Nutrition 2006, 22(78):697-704.

5. Sheil ML, Luxford C, Davies MJ, Peat JK, Nunn G, Celermajer DS: Protein oxidation injury occurs during pediatric cardiopulmonary bypass. The Journal of thoracic and cardiovascular surgery 2005, 130(4):10541061.

6. Roussin R, Belli E, Bruniaux J, Demontoux S, Touchot A, Planche C, Serraf A: Surgery for transposition of the great arteries in neonates weighing less than 2,000 grams: a consecutive series of 25 patients. The Annals of thoracic surgery 2007, 83(1):173-177; discussion 177-178.

7. Pizarro C, Davis DA, Galantowicz ME, Munro H, Gidding SS, Norwood WI: Stage I palliation for hypoplastic left heart syndrome in low birth weight neonates: can we justify it? European journal of cardio-thoracic surgery : official journal of the European Association for Cardio-thoracic Surgery 2002, 21(4):716-720.

8. Reddy VM, Hanley FL: Cardiac surgery in infants with very low birth weight. Semin Pediatr Surg 2000, 9(2):91-95.

9. Reddy VM, McElhinney DB, Sagrado T, Parry AJ, Teitel DF, Hanley FL: Results of $\mathbf{1 0 2}$ cases of complete repair of congenital heart defects in patients weighing $\mathbf{7 0 0}$ to $\mathbf{2 5 0 0}$ grams. The Journal of thoracic and cardiovascular surgery 1999, 117(2):324-331.

10. Chang AC, Hanley FL, Lock JE, Castaneda AR, Wessel DL: Management and outcome of low birth weight neonates with congenital heart disease. The Journal of pediatrics 1994, 124(3):461-466.

11. Reddy VM: Low birth weight and very low birth weight neonates with congenital heart disease: timing of surgery, reasons for delaying or not delaying surgery. Semin Thorac Cardiovasc Surg Pediatr Card Surg Annu 2013, 16(1):13-20.

12. Petrucci O, O'Brien SM, Jacobs ML, Jacobs JP, Manning PB, Eghtesady P: Risk factors for mortality and morbidity after the neonatal Blalock-Taussig shunt procedure. The Annals of thoracic surgery 2011, 92(2):642-651; discussion 651-642.

13. Padley JR, Cole AD, Pye VE, Chard RB, Nicholson IA, Jacobe S, Baines D, Badawi N, Walker K, Scarfe G et al: Five-year analysis of operative mortality and neonatal outcomes in congenital heart disease. Heart Lung Circ 2011, 20(7):460-467.

14. Wei D, Azen C, Bhombal S, Hastings L, Paquette L: Congenital Heart Disease in Low-Birth-Weight Infants: Effects of Small for Gestational Age (SGA) Status and Maturity on Postoperative Outcomes. Pediatric cardiology 2014.

15. Anderson JB, Kalkwarf HJ, Kehl JE, Eghtesady P, Marino BS: Low weight-for-age z-score and infection risk after the Fontan procedure. The Annals of thoracic surgery 2011, 91(5):1460-1466.

16. Anderson JB, Beekman RH, 3rd, Border WL, Kalkwarf HJ, Khoury PR, Uzark K, Eghtesady P, Marino BS: Lower weight-for-age $\mathrm{z}$ score adversely affects hospital length of stay after the bidirectional Glenn procedure in 100 infants with a single ventricle. The Journal of thoracic and cardiovascular surgery 2009, 138(2):397-404 e391.

17. Mehta NM, Bechard L, Cahill N, Wang M, Day A, Duggan CP, Heyland DK: Nutritional practices and their relationship to clinical outcomes in critically ill children--an international multicenter cohort study*. Critical care medicine 2012, 40(7):2204-2211.

18. Eskedal LT, Hagemo PS, Seem E, Eskild A, Cvancarova M, Seiler S, Thaulow E: Impaired weight gain predicts risk of late death after surgery for congenital heart defects. Archives of disease in childhood 2008, 93(6):495-501.

19. WHO: Management of Severe Malnutrition: A manual for Physicians and other Senior Health Workers. Geneva; 1999.

20. Jenkins KJ: Risk adjustment for congenital heart surgery: the RACHS-1 method. Semin Thorac Cardiovasc Surg Pediatr Card Surg Annu 2004, 7:180-184. 
21. Toole BJ, Toole LE, Kyle UG, Cabrera AG, Orellana RA, Coss-Bu JA: Perioperative nutritional support and malnutrition in infants and children with congenital heart disease. Congenit Heart Dis 2014, 9(1):15-25.

22. Medoff-Cooper B, Irving SY, Marino BS, Garcia-Espana JF, Ravishankar C, Bird GL, Stallings VA: Weight change in infants with a functionally univentricular heart: from surgical intervention to hospital discharge.

23. Medoff-Cooper B, Ravishankar C: Nutrition and growth in congenital heart disease: a challenge in children. Curr Opin Cardiol 2013, 28(2):122-129.

24. De Wit B, Meyer R, Desai A, Macrae D, Pathan N: Challenge of predicting resting energy expenditure in children undergoing surgery for congenital heart disease. Pediatric critical care medicine 2010, 11(4):496501.

25. Medoff-Cooper B, Naim M, Torowicz D, Mott A: Feeding, growth, and nutrition in children with congenitally malformed hearts. Cardiology in the young 2010, 20 Suppl 3:149-153.

26. Sables-Baus S, Kaufman J, Cook P, da Cruz EM: Oral feeding outcomes in neonates with congenital cardiac disease undergoing cardiac surgery. Cardiology in the young 2012, 22(1):42-48. 
Table 3 Legend:

Days free of all ventilation refers to days free of invasive and non-invasive modes of ventilation including 1 2 nasal CPAP and BIPAP. 
TABLE 1a:

Patient demographics

\begin{tabular}{|l|l|}
\hline Variable & Median (IQR) \\
\hline Weight $(\mathrm{kg})$ & $3.3(3$ to 3.6$)$ \\
\hline Age (days) & 7 (3 to 15) \\
\hline Weight-For-Age z score & $-0.77(-1.41$ to 0.01$)$ \\
\hline PIM2[24] Score & $8(3.5$ to 21.1$)$ \\
\hline Days free of invasive ventilatory support at & $25(22-26)$ \\
\hline 28 days & \\
\hline Days free of invasive and/or non-invasive & $24(20-26)$ \\
\hline respiratory support at 28 days & \\
\hline Days free of PICU at 28 days & $23.57(19.36-25.24)$ \\
\hline
\end{tabular}


Table 1b: Primary Cardiac Lesion

\begin{tabular}{|c|c|c|}
\hline Primary Cardiac Defect & $\mathbf{n}$ & $\%$ \\
\hline Atrio-ventricular Septal Defect & 3 & 1.2 \\
\hline Coarcation of the aorta & 65 & 26.2 \\
\hline $\begin{array}{l}\text { Transposition of the Great } \\
\text { Arteries }\end{array}$ & 94 & 37.9 \\
\hline Hypoplastic Right Heart & 1 & 0.4 \\
\hline Double outlet right ventricle & 13 & 5.2 \\
\hline Ebstein's Anomaly & 2 & 0.8 \\
\hline Hypoplastic Left Heart & 9 & 3.6 \\
\hline Interrupted Aortic arch & 11 & 4.4 \\
\hline Truncus arteriosus & 2 & 0.8 \\
\hline $\begin{array}{l}\text { Pulmonary Atresia (intact } \\
\text { ventricular septum) }\end{array}$ & 4 & 1.6 \\
\hline $\begin{array}{l}\text { Pulmonary Atresia (ventricular } \\
\text { septal defect) }\end{array}$ & 16 & 6.5 \\
\hline Pulmonary stenosis & 5 & 2 \\
\hline Hemitruncus & 1 & 0.4 \\
\hline Double inlet left ventricle & 2 & 0.8 \\
\hline Tetralogy of Fallot & 9 & 3.6 \\
\hline $\begin{array}{l}\text { Total anomalous pulmonary } \\
\text { venous drainage }\end{array}$ & 5 & 2 \\
\hline Tricuspid atresia & 5 & 2 \\
\hline Ventricular septal defect & 1 & 0.4 \\
\hline Total & 248 & 100 \\
\hline
\end{tabular}


Table 2: analysis of clinical variables based on malnutrition group (normal, mild or moderate malnutrition) based on admission WAZ score.

\begin{tabular}{|c|c|c|c|c|}
\hline & & Normal WAZ (+1 to -1$)$ & $\begin{array}{l}\text { Mild malnutrition } \\
\text { (WAZ less than }-1 \text { to - } \\
\text { 2) }\end{array}$ & $\begin{array}{l}\text { Moderate } \\
\text { malnutrition (WAZ } \\
\text { less than -2) }\end{array}$ \\
\hline \multirow[t]{3}{*}{ Agedays } & Count & 151.00 & 70.00 & 27.00 \\
\hline & Median & 7.00 & 10.00 & 8.00 \\
\hline & IQR & 2 to 12 & 4 to 17 & 2 to 21 \\
\hline \multirow[t]{3}{*}{ Weight } & Count & 151.00 & 70.00 & 27.00 \\
\hline & Median & 3.60 & 3.00 & 2.30 \\
\hline & IQR & 3.3 to 3.75 & 2.8 to 3.1 & 2.1 to 2.6 \\
\hline \multirow{3}{*}{$\begin{array}{c}\text { Days free of PICU at } 28 \\
\text { days }\end{array}$} & Count & 151.00 & 70.00 & 27.00 \\
\hline & Median & 24.00 & 23.23 & 22.87 \\
\hline & IQR & 20 to 25 & 21 to 25.3 & 1.29 to 24.79 \\
\hline \multirow{3}{*}{$\begin{array}{l}\text { Days free of invasive } \\
\text { ventilation at } 28 \text { days }\end{array}$} & Count & 151 & 70 & 27.00 \\
\hline & Median & 25.0 & 24.5 & 24.00 \\
\hline & IQR & 22 to 26 & 21 to 26 & 18 to 26 \\
\hline \multirow{3}{*}{$\begin{array}{l}\text { Days free of all } \\
\text { respiratory support at } 28 \\
\text { days }^{*}\end{array}$} & Count & 151.00 & 70.00 & 27.00 \\
\hline & Median & 25.00 & 23.50 & 14.00 \\
\hline & IQR & 21 to 26 & 20 to 26 & 0 to 25 \\
\hline
\end{tabular}

${ }^{*} \mathrm{P}=0.006$ 
Table 3a: Analysis of independent variables on post-operative morbidity (respiratory support and intensive care stay).

\begin{tabular}{|c|c|c|c|c|}
\hline & $\begin{array}{l}\text { Days Free of } \\
\text { Invasive } \\
\text { Ventilation at } \\
28 \text { Days }\end{array}$ & $\begin{array}{l}\text { Days Free of all } \\
\text { ventilation at } 28 \\
\text { Days }\end{array}$ & $\begin{array}{l}\text { Days free of PICU } \\
\text { at } 28 \text { Days }\end{array}$ & $\begin{array}{l}\text { Post-operative } \\
\text { survival }\end{array}$ \\
\hline $\begin{array}{l}\text { Weight for } \\
\text { age z-score }\end{array}$ & 0.17 & 0.0005 & 0.08 & 0.31 \\
\hline Gender & 0.95 & 0.41 & 0.41 & 0.63 \\
\hline Age & 0.7 & 0.39 & 0.5 & 0.04 \\
\hline Lactate & $<0.0001$ & $<0.0001$ & $<0.0001$ & $<0.0001$ \\
\hline $\begin{array}{l}\text { RACH score } \\
3\end{array}$ & 0.5 & 0.72 & 0.17 & 0.41 \\
\hline $\begin{array}{l}\text { RACH score } \\
4\end{array}$ & 0.003 & 0.004 & 0.001 & 0.77 \\
\hline $\begin{array}{l}\text { RACH score } \\
6\end{array}$ & $<0.0001$ & $<0.0001$ & $<0.0001$ & 0.005 \\
\hline PIM & 0.31 & 0.35 & 0.98 & 0.73 \\
\hline
\end{tabular}


Table 3b: Multivariate analysis of common factors in critically ill children with cardiac disorders on survival status at 1 year of age

\begin{tabular}{|c|c|c|c|c|}
\hline & Odds Ratio & $\begin{array}{l}\text { 95\% Confide } \\
\text { Lower }\end{array}$ & nce Interval & $\begin{array}{l}\text { Statistical } \\
\text { significance }\end{array}$ \\
\hline $\begin{array}{l}\text { Weight-for-age } \\
\text { Z score }\end{array}$ & 2.36 & 1.36 & 4.28 & 0.002 \\
\hline Gender & 0.77 & 0.28 & 2.14 & 0.61 \\
\hline Age (in days) & 1.1 & 1.03 & 1.18 & 0.006 \\
\hline Lactate & 0.77 & 0.69 & 0.84 & $<0.0001$ \\
\hline RACH score 3 & 1.13 & 0.33 & 3.53 & 0.82 \\
\hline RACH score 4 & 1.19 & 0.21 & 8.32 & 0.84 \\
\hline RACH score 6 & 0.63 & 0.09 & 4.55 & 0.64 \\
\hline PIM score & 0.99 & 0.97 & 1.01 & 0.43 \\
\hline
\end{tabular}


